\title{
Ghrelin accelerates the cartilagic differentiation of rabbit mesenchymal stem cells through the ERK1/2 pathway
}

\author{
Nan Ye $\cdot$ Lin Wang $\cdot$ Zhe Dou $\cdot$ Jian Huang
}

Received: 31 May 2017 / Accepted: 20 October 2017/Published online: 12 December 2017

(C) Springer Science+Business Media B.V. 2017

\begin{abstract}
Mesenchymal stem cells (MSCs) can differentiate into chondroblasts, adipocytes, or cartilage under appropriate stimulation. Identifying a mechanism triggering the differentiation of MSCs into cartilage may help develop novel therapeutic approaches for treating heterotopic ossification, the pathological formation of lamellar bone in soft tissue outside the skeleton that can lead to debilitating immobility. Ghrelin, an endogenous ligand for the growth hormone secretagogue receptor, stimulates growth hormone secretion, and has both orexigenic and adipogenic effects. This study sought to understand the potential involvement of the ERK1/2 signaling pathway in the ghrelin-induced growth of rat MSCs (rMSCs). We applied various concentrations of ghrelin to cultured rMSCs by observing the changes in the phosphorylation state of ERK1/2, p38, JNK as well as the type II collagen expression levels by western blot. The highest expression level for both type II collagen was obtained with $600 \mathrm{ng} / \mathrm{mL}$ ghrelin at $24 \mathrm{~h}$. We found that the ghrelin-induced differentiation of rMSCs into cartilage was promoted primarily by the ERK1/2 pathway. Our study suggests that ghrelin induced differentiation of rMSCs into cartilage primarily through the ERK1/2 pathway.
\end{abstract}

N. Ye $\cdot$ L. Wang $\cdot$ Z. Dou $\cdot$ J. Huang $(\bowtie)$

Department of Cervical Surgery, The Second Affiliated Hospital of Inner Mongolia Medical University, Muslims Camp Square Road No 1, Hohhot, China

e-mail: huangjian1122@126.com
Keywords rMSCs - MAPK · Ghrelin · Cartilage differentiation $\cdot$ ERK1/2

\section{Introduction}

Bone marrow-derived mesenchymal cells (BMSCs) are among the best characterized of all stem cells studied so far, with great differentiation ability and being able to secrete factors beneficial for tissue repair (Zhu et al. 2013; Yin et al. 2016). Besides, they are of low immunogenicity and can exert potent immunosuppression (Zhou et al. 2016a, b). Moreover, MSCs have been widely reported to exert angiogenesis in in vitro and in vivo experiments (Zheng et al. 2016). Basic research on MSCs in certain fields has led to the initiation of clinical trials worldwide (Zhao et al. 2016b). To provide therapeutic benefits and further understand the mechanisms responsible for them, large numbers of cells are needed (Zhao et al. 2016a).

Ghrelin, a 28-amino-acid peptide identified as the first endogenous ligand for the growth hormone secretagogue receptor (GHS-R) (Xu et al. 2008; Wu et al. 2015), is found mainly in stomach and hypothalamus where it exercises biological activities such as regulating food intake and stimulating the release of growth hormone (GH) (Tena-Sempere 2005). It has been recently reported that ghrelin is also synthesized and secreted by cardiomyocytes and that ghrelin treatment inhibits cell death and apoptosis and 
Fig. 1 Identification of rMSCs.

a Immunofluorescence staining showing the expression of CD34 and CD44 in cultured rMSCs. Scale bar: $50 \mu \mathrm{m}$. b Flow cytometry showing the expression of CD34 and CD44 in cultured rMSCs
A

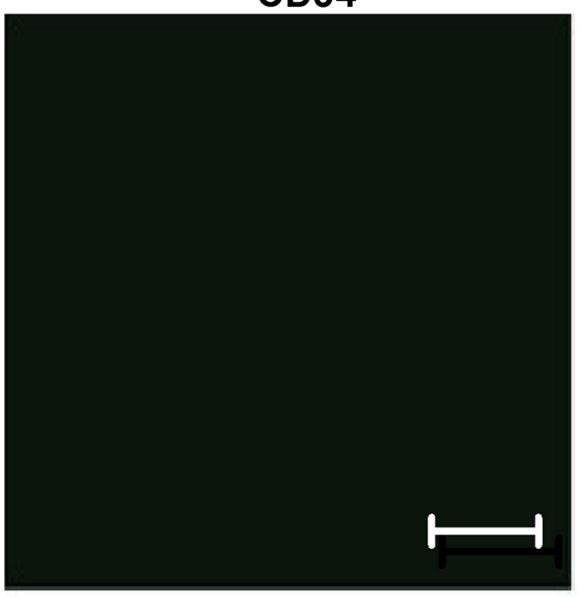

CD34

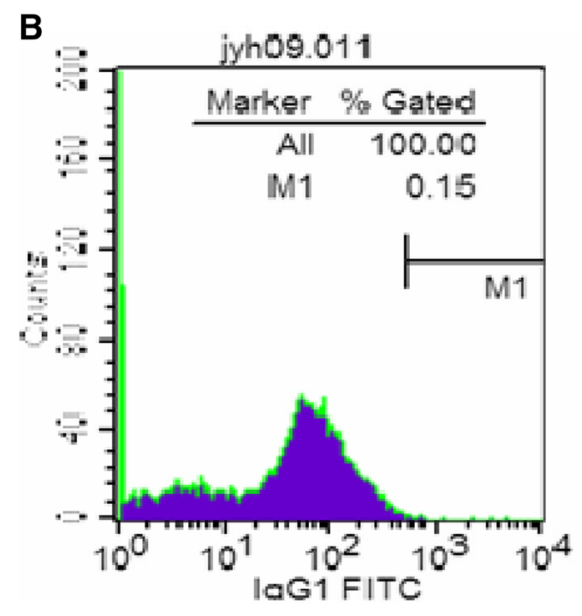

CD34
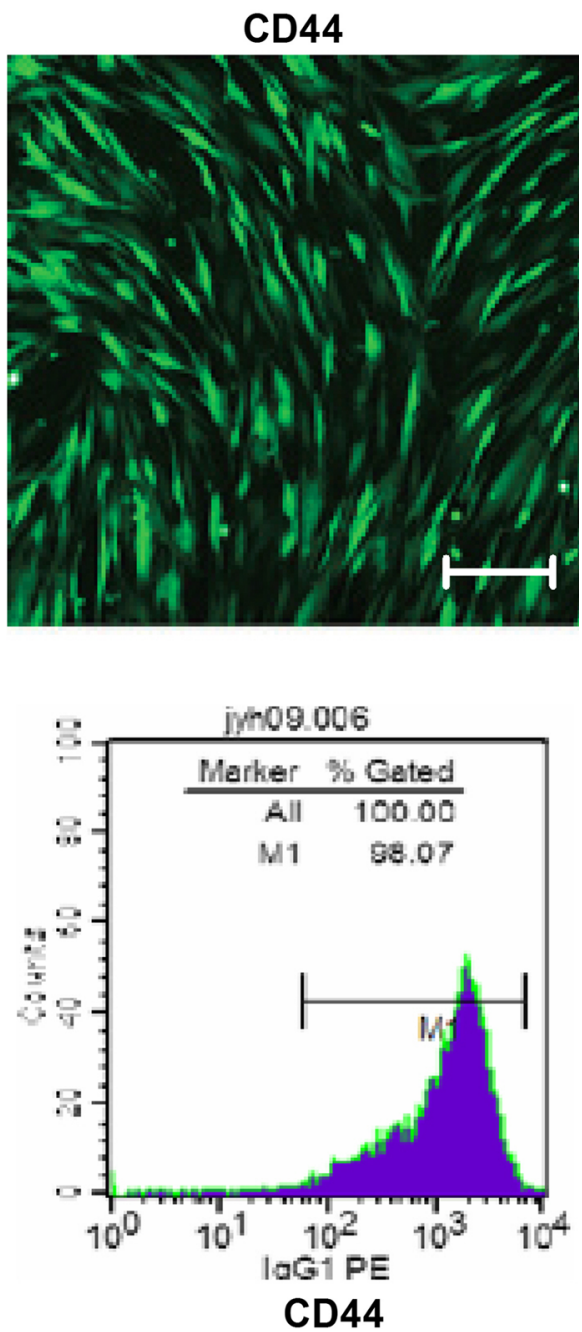

promotes cell proliferation in cardiomyocytes (Tack and Corsetti 2015). In addition, several studies have shown that ghrelin is involved in regulating the differentiation of mesoderm-derived precursor cells including premyocyt, osteoblast, and preadipocyte either in vivo or in vitro (St-Onge et al. 2016; Shi et al. 2016).

Cellular signaling is essential for the cells' ability to respond to the environment by integrating external cues to intracellular mediators and effectors. Activation of mitogen-activated protein kinases (MAPKs) constitutes a paradigm of intracellular signaling (Zhang et al. 2015, 2016). p38, a subgroup of the MAPKs, was initially identified as a transducer of the response to inflammatory and environmental stress conditions (Zhang et al. 2015, 2016; Xie et al. 2014).
Phosphorylation of these threonine and tyrosine residues results in a conformational change that increases the accessibility of the active site and enhances catalysis (Urosevic et al. 2014). ERKs are activated in response to various cytokines and growth factors and mediate primarily mitogenic and antiapoptotic signals (Smith et al. 2014).

Previously, we have found ghrelin is a growth factor important for the proliferation of mesenchymal stem cells, as well as essential to promote the differentiation of the mesenchymal stem cells to osteoblast cell. However, the effect of ghrelin on cartilage cells was not shown. In this study, ghrelin effects on the differentiation of the mesenchymal stem cells to cartilage cells was studied. 


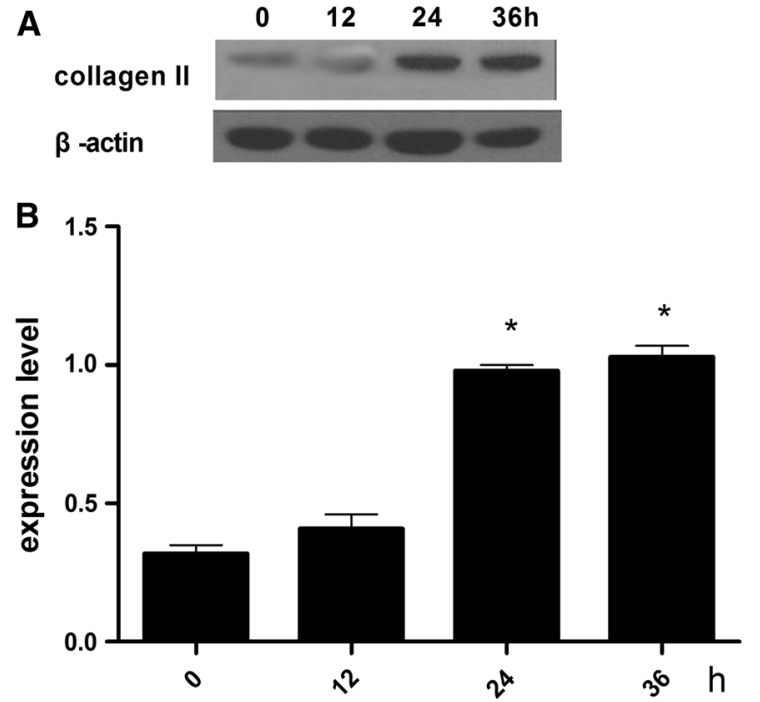

Fig. 2 Expression levels of type II collagen in cartilage induced by standard differentiation-inducing medium supplemebted with $600 \mathrm{ng} / \mathrm{mL}$ ghrelin. a Expression of type II collagen assessed by western blot. b Contrast gray value of type II collagen based on the western blot, presented as mean $\pm \mathrm{SD}$ $(\mathrm{n}=5)$. *Significantly different from the 0 h group $(P<0.05)$. Contrast gray value of type II collagen $=$ gray value of type II collagen/gray value of $\beta$-actin

\section{Materials and methods}

Unless otherwise specified, all chemicals and reagents were purchased from Sigma Chemical Company (St. Louis, MO, USA). Antibodies to IgG, GAPDH, ALP, Runx2, Osterix, CD44, CD34, U0126 (an inhibitor of phospho-ERK1/2) ERK1/2, JNK, p90 ${ }^{\text {rsk }}$, phosphoERK1/2, phospho-JNK and phospho-p90 ${ }^{\text {rsk1 }}$ (Ser380) were purchased from the Abcam Corporation Cambridge, MA, USA). ECL regent was purchased Pierce (Rockford, IL, USA). Alexa Fluor 488 goat anti-rabbit $\operatorname{IgG}(\mathrm{H}+\mathrm{L})$ secondary antibody was purchased from Abcam Corporation.

Isolation and culture of rMSCs

The rMSCs were obtained from a neonatal New Zealand white rabbit. The bone marrow was flushed with low glucose Dulbecco's modified Eagle's medium (DMEM) using a $1 \mathrm{~mL}$ syringe. Cells were harvested in culture dish, cultured in an incubator at $37{ }^{\circ} \mathrm{C}$ with $5 \% \quad \mathrm{CO}_{2}$. The animal protocol was approved by The Inner Mongolia Medical University Experimental Animal Management Committee.
A
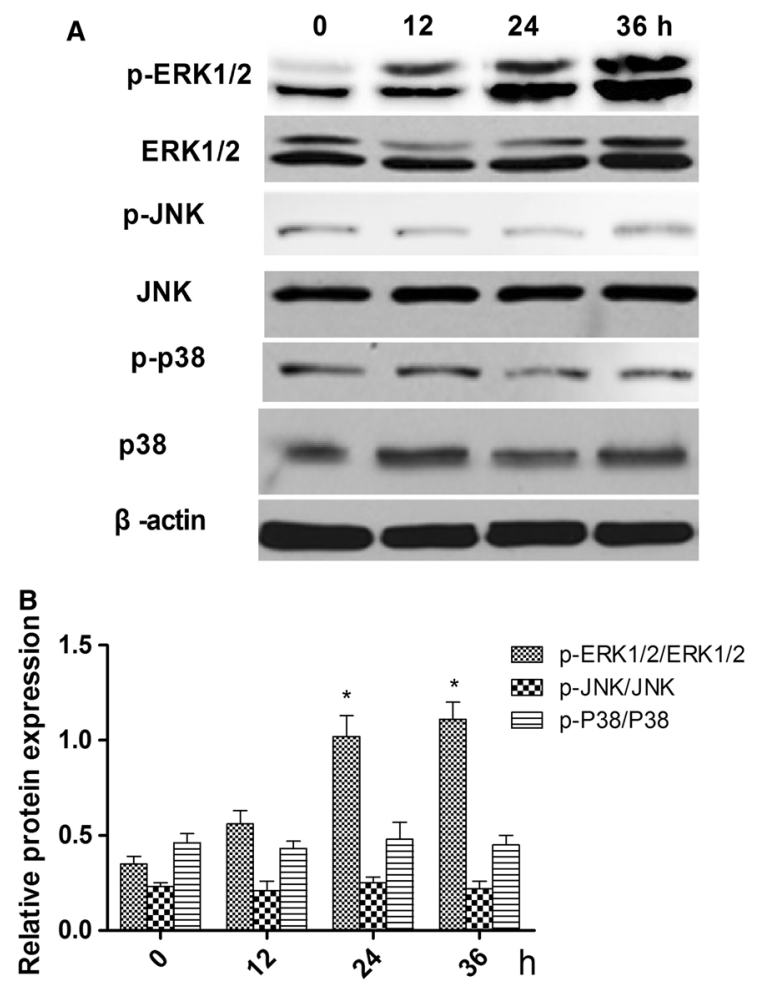

Fig. 3 Effects of $600 \mathrm{ng} / \mathrm{ml}$ ghrelin on mitogen-activated protein kinase (MAPK) activation in rBMSCs cells. a Expression of total and phosphorylated ERK1/2, JNKs, and p38 proteins. b Ratios of phosphorylated to non-phosphorylated ERK1/2, JNKs, and p38 based on the western blot, presented as mean $\pm \mathrm{SD}(\mathrm{n}=5)$. *Significantly different from the 0 h group $(P<0.05)$. Contrast gray value of phosphorylation protein $=$ gray value of phosphorylated protein/gray value of non-phoshporylated protein

Immunofluorescence

The rMSCs, at room temperature, were fixed in $3.7 \%$ paraformaldehyde for half an hour. Blocked with $1 \%$ bovine serum albumin in PBS with $10 \%$ goat serum overnight at $4{ }^{\circ} \mathrm{C}$. The samples were then incubated with primary antibodies diluted in PBS. The primary antibody binding was detected with an Alexa Fluor 488 goat anti-rabbit $\operatorname{IgG}(\mathrm{H}+\mathrm{L})$ secondary antibody. The fluorescence images were captured with a microscope.

Flow cytometric analysis

Cells were stained with the following antibodies: fluorescein isothiocyanate (FITC)-conjugated monoclonal antibodies against rat CD44, CD34. Cells were 
Fig. 4 Effects of addition of U1206 in combination with $600 \mathrm{ng} / \mathrm{mL}$ of ghrelin on the expression of ERK1/ 2, p-ERK $1 / 2$ and type II collagen proteins. a Expression of total and phosphorylated ERK1/2 proteins. b Ratio of the contrast gray value of phosphorylation to nonphosphorylated ERK1/2 based on the western blot. c Expression of type II collagen. d Contrast gray value of type II collagen based on the western blot, presented as mean $\pm \mathrm{SD}$ $(\mathrm{n}=5)$. *Significantly different from the $0 \mathrm{~h}$ group $(P<0.05)$
A

B

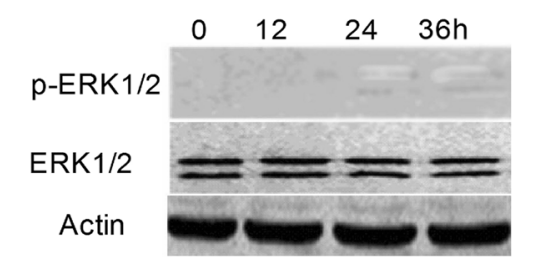

C

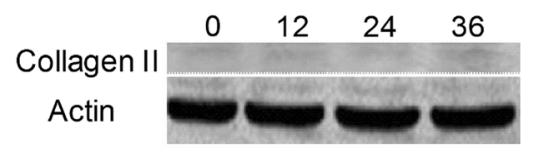

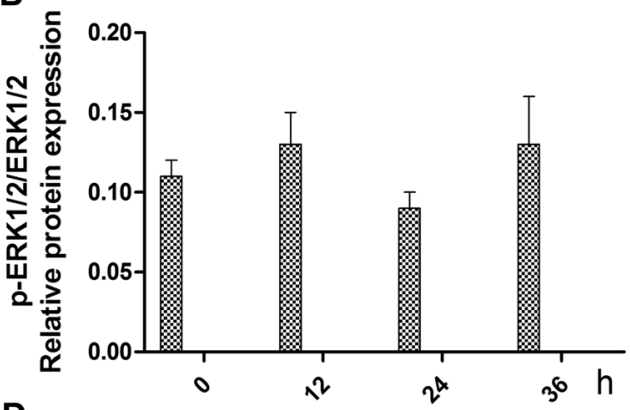

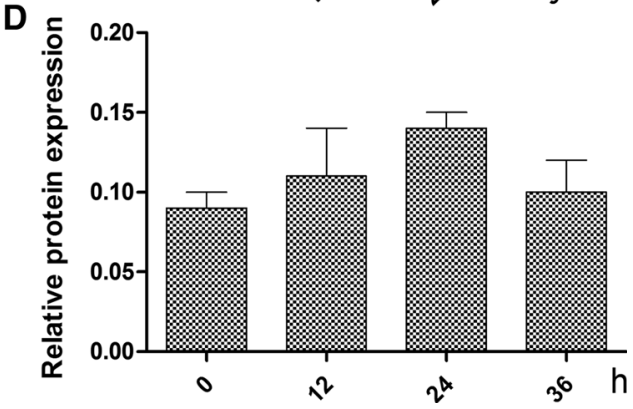

also stained with FITC- or PE-labeled isotypematched immunoglobulins and used as negative controls. The stained cells were analyzed using a FACSCalibur cytometer and CellQuest software (Becton, Dickinson and Company, Franklin Lakes, NJ, USA).

\section{Western blotting}

The protein, obtained from rMSCs, were separated using electrophoresis on $12 \%$ SDS-PAGE and transferred to immunoblot nitrocellulose membranes. Membranes were blocked and then incubated with primary antibodies overnight at $4{ }^{\circ} \mathrm{C}$. The membranes were subsequently washed three times with PBS, incubated with peroxidase-conjugated secondary antibodies. Using ECL reagents to reveal the results (Pierce, Rockford, IL, USA).

\section{Cartilage differentiation}

The rMSCs were plated at a density of 5000 cells $/ \mathrm{cm}^{2}$ and exposed to standard differentiation-inducing media for 21 days. The medium $(5 \mu \mathrm{g} / \mathrm{ml}$ insulin, $5 \mu \mathrm{g} / \mathrm{ml}$ transferrin, $5 \mu \mathrm{g} / \mathrm{ml}$ selenous acid, $0.1 \mathrm{M}$ dexamethasone, $0.17 \mathrm{mM}$ ascorbic acid-2-phosphate, $1 \mathrm{mM}$ sodium pyruvate, $0.35 \mathrm{mM}$ proline, $1.25 \mathrm{mg} /$ $\mathrm{ml} \mathrm{BSA}$, and $10 \mu \mathrm{g} / \mathrm{ml}$ transforming growth factor beta 3) was changed twice per week. Cartilage differentiation was achieved following standard in vitro protocols (Fromigué et al. 1998).

Statistical analysis

One-way analysis of variance (ANOVA) with GraphPad Prism version 5 software (GraphPad Software, La Jolla, CA, USA, www.graphpad.com/company/) was used for statistical analysis of the data. Data are presented as mean \pm S.D.

\section{Results}

Identification of rMSCs

On day 10 , cells reached $80 \%$ confluence. On day 13 , the cells displayed a uniform spindle shape and reached $100 \%$ confluence. To further identify the rMSCs, the expression of CD34 and CD44 was examined by immunofluorescence. The cells were CD44 positive but CD34 negative (Fig. 1a). Flow cytometric analysis showed that the isolated cells strongly expressed the surface markers of mesenchymal stem cells, such as CD44, but almost no markers CD34 (Fig 1B). 


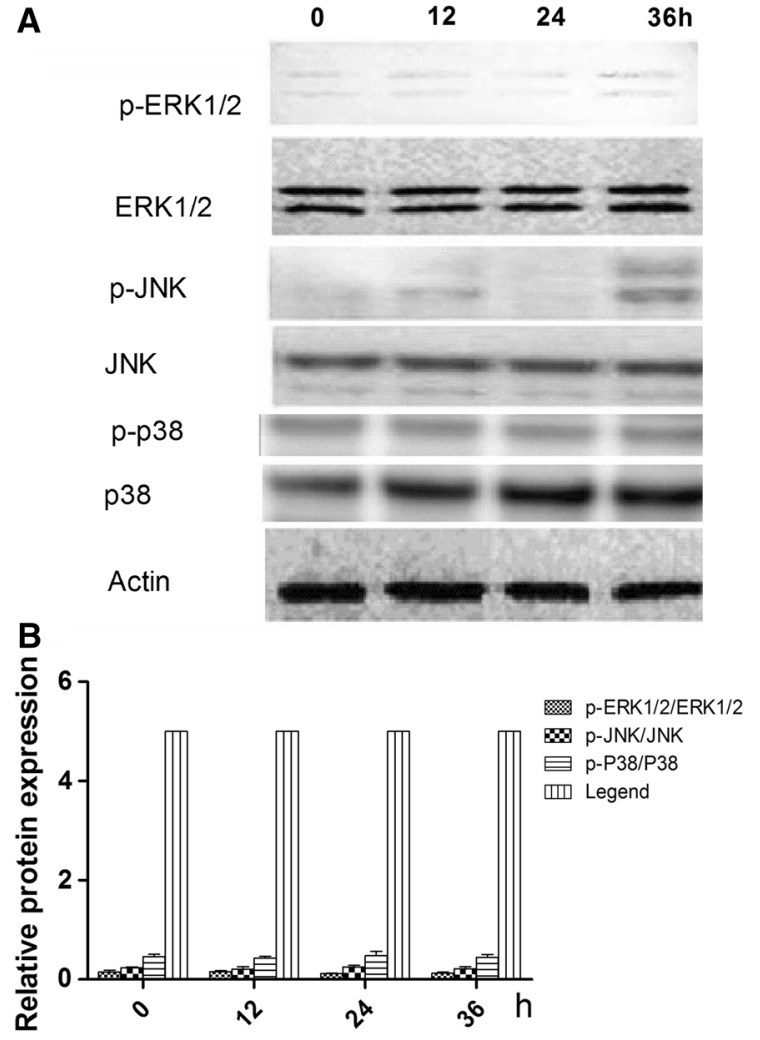

Fig. 5 Effects of ghrelin receptor inhibitor (D-Lys3-GHRP-6) in combination with $600 \mathrm{ng} / \mathrm{mL}$ of ghrelin on ghrelin-mediated MAPK activation in rMSCs cells. a Expression of total and phosphorylated ERK1/2, JNKs, and p38 proteins. b Contrast gray value of phosphorylation of ERK1/2, JNKs and p38 based on the western blot, presented as mean $\pm \operatorname{SD}(n=5)$. Ratios of phosphorylated to non-phosphorylated protein $=$ gray value of phosphorylation protein/ gray value of protein. *Significantly different from the $0 \mathrm{~h}$ group $(P<0.05)$

Optimal time for ghrelin-induced effects on the differentiation of rMSCs into cartilage

The optimal of ghrelin for the effects on the differentiation of rMSCs into cartilage was established. Figure 2 shows the expression levels of type II collagen and glycosaminoglycan at a ghrelin concentration of $600 \mathrm{ng} / \mathrm{mL}$ at $0,12,24$, and $36 \mathrm{~h}$. The highest expression level for both type II collagen was in presence of $600 \mathrm{ng} / \mathrm{mL}$ ghrelin at $24 \mathrm{~h}$.

Ghrelin promotes the differentiation of rMSCs into cartilage via the ERK1/2 pathway

To identify the signaling pathway through which ghrelin acts to promote the differentiation of rMSCs

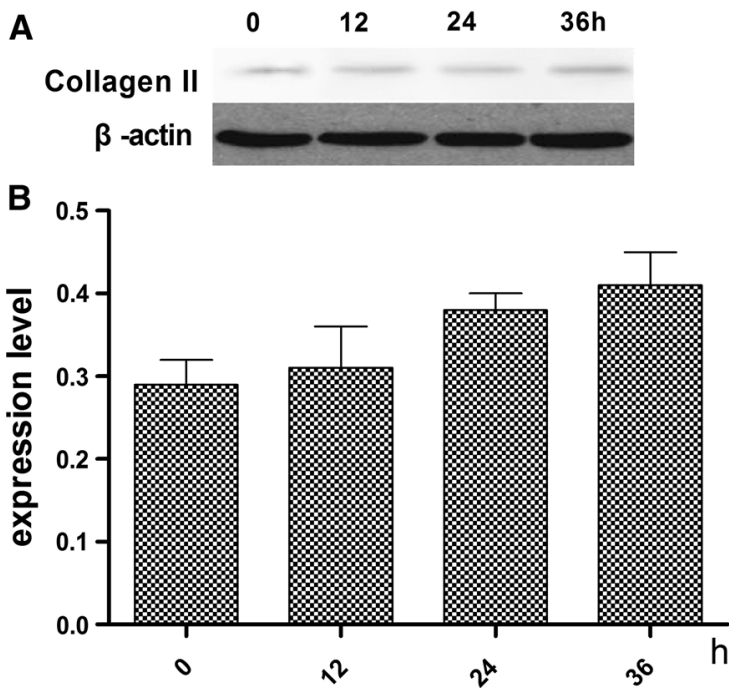

Fig. 6 Expression of type II collagen by cartilage after treatment with the ghrelin receptor inhibitor (D-Lys3-GHRP6) in combination with $600 \mathrm{ng} / \mathrm{mL}$ of ghrelin. a Expression of type II collagen by western blot. b Contrast gray value of type II collagen based on the western blot, presented as mean \pm SD $(n=5)$. Contrast gray value of type II collagen = gray value of type II collagen/gray value of $\beta$-actin. *Significantly different from the $0 \mathrm{~h}$ group $(P<0.05)$

into cartilage, cells were treated with $600 \mathrm{ng} / \mathrm{mL}$ of ghrelin for $0,12,24$ and $36 \mathrm{~h}$, and the phosphorylation levels of ERK1/2, JNK, p38 were examined on 0, 12, 24 , and 36 h (Fig. 3a). Figure $3 \mathrm{~b}$ shows that the ratios of phosphorylated to non-phosphorylated ERK1/2 were higher on 24 and $36 \mathrm{~h}$ than on 0 and $12 \mathrm{~h}$.

To verify that ghrelin promotes the differentiation of rMSCs into cartilage via the ERK1/2 pathway, the ERK1/2 signaling inhibitor U0126 (a specific inhibitor of ERK1/2 phosphorylation) was used to inhibit ERK1/2 phosphorylation activity. Following the addition of U0126, the cells were treated with ghrelin for 0 , 12,24 , and $36 \mathrm{~h}$. We found that the phosphorylation of ERK1/2 was not changed and was low (Fig. 4a, b). In addition, the expression levels of type II collagen were not changed and were very low (Fig. 4c, d).

When this treatment was repeated with the addition of $10^{-9} \mathrm{mg} / \mathrm{ml}$ D-Lys3-GHRP-6, compared with treatment with ghrelin only, the phosphorylation of ERK1/2 was reduced (Fig. 5a). The phosphorylation status of the JNKs and p38 were not significantly modified (Fig. 5b), nor were the levels of type II collagen (Fig. 6).

This result suggests that ERK1/2 plays a key role in ghrelin's ability to accelerate the growth of rMSCs. To 
test this, U0126 (a specific inhibitor of ERK1/2 phosphorylation) was used to silence ERK1/2 expression. In the presence of U0126, ghrelin (600 ng/ml) did not accelerate the expression levels of type II collagen.

\section{Discussion}

It may help to develop novel therapeutic approaches for treating heterotopic ossification, and to find trigger the differentiation of rMSCs into cartilage mechanisms (Kara et al. 2015). Here, the ghrelin-induced differentiation of rMSCs into cartilage was promoted primarily via the ERK1/2 pathway was shown, and when U0126 was added, the function of ghrelin inducing differentiation of rMSCs into cartilage was inhibited.

Ghrelin, an endogenous ligand for the growth hormone secretagogue receptor (GHSR), is a 28-amino-acid peptide produced from a 117-amino acid preprohormone (Rambhojan et al. 2015). It has been recently reported that ghrelin is also synthesized and secreted by cardiomyocytes and that ghrelin treatment inhibits cell death and apoptosis and promotes cell proliferation in cardiomyocytes (Moon et al. 2009; Gao et al. 2013). Previously, we have found that ghrelin $(600 \mathrm{ng} / \mathrm{ml})$ can promote the growth of rMSCs and the rMSCs differentiation to osteoblast cell. Ghrelin/GHSR signaling pathway accelerates rMSC growth and promotes rMSC differentiation to osteoblasts mainly through an ERKdependent pathway (Ye and Jiang 2015). In this study, we found that ghrelin can promote the rMSCs differentiation to cartilage, especially at $24 \mathrm{~h}$. At that time, as the marker protein, the type II collagen was expressed at higher levels at $24 \mathrm{~h}$ than at 0 and $12 \mathrm{~h}$.

In this study, we found that the ghrelin-induced differentiation of rMSCs into cartilage was promoted primarily through the ERK1/2 pathway. The MAPKs are a super-family of serine/threonine kinases that include ERK, JNK, and p38 (Rodriguez-Pena et al. 2013). These kinases are involved primarily in the activation of nuclear transcription factors that control cell proliferation, differentiation, and apoptosis (Qiu et al. 2014). To verify the ERK1/2 function, the U1206 was used to inhibit the ERK1/2 phosphorylation activity. The type II collagen expression was reduced. Therefore, the function of rMSCs differentiation to cartilage was also inhibited. Further, the gherlin receptor (GHRS) was inhibited by D-Lys3-GHRP-6. We also found that type II collagen expressed was inhibited and the rMSCs differentiation to cartilage was also inhibited.

Overall, our results provide evidence that the ghrelin/GHSR signaling pathway promotes rMSC differentiation to cartilage mainly through an ERKdependent pathway. In this study, we found that the ghrelin-induced differentiation of rMSCs into cartilage was promoted primarily bythe ERK1/2 pathway. Further studies are necessary before any clinical application is considered.

Acknowledgement This work was supported by Inner Mongolia Natural Science Foundation (No. 2017BS0813).

\section{References}

Fromigué O, Marie PJ, Lomri A (1998) Bone morphogenetic protein-2 and transforming growth factor- $\hat{\mathrm{I}}^{2} 2$ interact to modulate human bone marrow stromal cell proliferation and differentiation. J Cell Biochem 68:411-426

Gao M, Yang J, Wei R, Liu G, Zhang L, Wang H, Wang G, Gao H, Chen G, Hong T (2013) Ghrelin induces cardiac lineage differentiation of human embryonic stem cells through ERK1/2 pathway. Int J Cardiol 167:2724-2733

Kara M, Ekiz T, Ozturk GT, Onat SS, Ozcakar L (2015) Heterotopic ossification and peripheral nerve entrapment: ultrasound is a must-use imaging modality. Pain Med 16:1643-1644

Moon M, Kim S, Hwang L, Park S (2009) Ghrelin regulates hippocampal neurogenesis in adult mice. Endocr $\mathrm{J}$ 56:525-531

Qiu W, Chen N, Zhang Q, Zhuo L, Wang X, Wang D, Jin H (2014) Resistin increases platelet P-selectin levels via p38 MAPK signal pathway. Diab Vasc Dis Res 11:121-124

Rambhojan C, Bouaziz-Amar E, Larifla L, Deloumeaux J, Clepier J, Plumasseau J, Lacorte JM, Foucan L (2015) Ghrelin, adipokines, metabolic factors in relation with weight status in school-children and results of a 1-year lifestyle intervention program. Nutr Metab (Lond) 12:43

Rodriguez-Pena JM, Diez-Muniz S, Bermejo C, Nombela C, Arroyo J (2013) Activation of the yeast cell wall integrity MAPK pathway by zymolyase depends on protease and glucanase activities and requires the mucin-like protein Hkr1 but not Msb2. FEBS Lett 587:3675-3680

Shi L, Du X, Jiang H, Xie J (2016) Ghrelin and neurodegenerative disorders - a review. Mol Neurobiol 54:1144-1155

Smith MP, Sanchez-Laorden B, O'Brien K, Brunton H, Ferguson J, Young H, Dhomen N, Flaherty KT, Frederick DT, Cooper ZA et al (2014) The immune microenvironment confers resistance to MAPK pathway inhibitors through macrophage-derived TNFalpha. Cancer Discov 4:1214-1229 
St-Onge V, Watts A, Abizaid A (2016) Ghrelin enhances cueinduced bar pressing for high fat food. Horm Behav 78:141-149

Tack J, Corsetti M (2015) Ghrelin agonists as emerging prokinetic agents. Clin Gastroenterol Hepatol 13:2320-2322

Tena-Sempere M (2005) Ghrelin: novel regulator of gonadal function. J Endocrinol Invest 28:26-29

Urosevic J, Nebreda AR, Gomis RR (2014) MAPK signaling control of colon cancer metastasis. Cell Cycle 13:2641-2642

Wu W, Fan X, Yu Y, Wang Y (2015) Maternal serum ratio of ghrelin to obestatin decreased in preeclampsia. Pregnancy Hypertens 5:263-266

Xie Y, Peng Z, Shi M, Ji M, Guo H, Shi H (2014) Metformin combined with p38 MAPK inhibitor improves cisplatin sensitivity in cisplatinresistant ovarian cancer. Mol Med Rep 10:2346-2350

Xu G, Li Y, An W, Zhang W (2008) Ghrelin and cell differentiation. Acta Biochim Biophys Sin (Shanghai) 40:841-847

Ye N, Jiang D (2015) Ghrelin accelerates the growth and osteogenic differentiation of rabbit mesenchymal stem cells through the ERK1/2 pathway. BMC Biotechnol 15:51

Yin Q, Zhou YY, Wang P, Ma LI, Li P, Wang XG, She CH, Li WL (2016) CD44 promotes the migration of bone marrowderived mesenchymal stem cells toward glioma. Oncol Lett 11:2353-2358

Zhang C, Shi J, Mao SY, Xu YS, Zhang D, Feng LY, Zhang B, Yan YY, Wang SC, Pan JP et al (2015) Role of p38 MAPK in enhanced human cancer cells killing by the combination of aspirin and ABT-737. J Cell Mol Med 19:408-417
Zhang R, Lu M, Zhang Z, Tian X, Wang S, Lv D (2016) Resveratrol reverses P-glycoprotein-mediated multidrug resistance of U2OS/ADR cells by suppressing the activation of the NF-kappaB and p38 MAPK signaling pathways. Oncol Lett 12:4147-4154

Zhao X, Hwang NS, Bichara DA, Saris DB, Malda J, Vacanti JP, Pomerantseva I, Sundback CA, Langer R, Anderson DG, Randolph MA (2016a) Chondrogenesis by bone marrowderived mesenchymal stem cells grown in chondrocyteconditioned medium for auricular reconstruction. J Tissue Eng Regen Med 11:121-125

Zhao Y, Wang X, Dong P, Xu Q, Ma Z, Mu Q, Sun X, Jiang Z (2016b) Bone marrow derived mesenchymal stem cells alleviated brain injury via down-regulation of interleukin$1 \beta$ in focal cerebral ischemic rats. Am $J$ Transl Res $8: 1541-1550$

Zheng Y, Cai W, Zhou S, Xu L, Jiang C (2016) Protective effect of bone marrow derived mesenchymal stem cells in lipopolysaccharide-induced acute lung injury mediated by claudin-4 in a rat model. Am J Transl Res 8:3769-3779

Zhou J, Carter BZ, Andreeff M (2016a) Bone-marrow-derived mesenchymal stem cells inhibit gastric aspiration lung injury and inflammation in rats. $\mathrm{J}$ Cell Mol Med 20:1706-1717

Zhou HS, Carter BZ, Andreeff M (2016b) Bone marrow nichemediated survival of leukemia stem cells in acute myeloid leukemia: Yin and Yang. Cancer Biol Med 13:248-259

Zhu S, Zhang T, Sun C, Yu A, Qi B, Cheng H (2013) Bone marrow mesenchymal stem cells combined with calcium alginate gel modified by hTGF-beta1 for the construction of tissue-engineered cartilage in three-dimensional conditions. Exp Ther Med 5:95-101 